\title{
Medicolegal
}

\section{Death from interventionist radiology: a cautionary tale}

\author{
CLARE DYER
}

On 23 February 1985 James McAlpine, aged 7, underwent a neuroradiological procedure at Ross Hall, a private hospital in Glasgow, to improve the appearance of a haemangioma on his lower lip. The procedure, external carotid embolisation, entails two steps: angiography to show up the arterial layout is followed by insertion of embolic material, in this case a gel foam, into the external carotid artery. Within 24 hours James was dead, through cerebral damage caused by occlusion of the right middle cerebral artery by the gel foam. His parents had not been warned that there were any risks attached to the procedure, which they had been led to believe was a straightforward one. Nor had they been told that Mr Martyn Webster, the plastic surgeon who recommended the operation and arranged for it to be carried out at Ross Hall, had a substantial financial interest in the hospital.

A fatal accident inquiry concluded that the death might have been avoided if the parents had been more fully informed of the nature of the procedure and its hazards and if the child had been more closely monitored postoperatively. Last July the General Medical Council suspended Mr Webster and Dr George Vaughan, the neuroradiologist who carried out the procedure, for six months for serious professional misconduct, and last month their employing authorities, the Greater Glasgow and the Lothian health boards, terminated their consultant contracts.

\section{A new paragraph from the GMC}

A new paragraph added last year to the GMC's "blue book," Professional Conduct and Discipline: Fitness to Practise, states: "The public are entitled to expect that a registered medical practitioner will afford and maintain a good standard of medical care. This includes: $(a)$ conscientious assessment of the history, symptoms and signs of a patient's condition; $(b)$ sufficiently thorough professional attention, examination and, where necessary, diagnostic investigation; $(c)$ competent and considerate professional management; $(d)$ appropriate and prompt action upon evidence suggesting the existence of a condition requiring urgent medical intervention; and $(e)$ readiness, where the circumstances so warrant, to consult appropriate professional colleagues." At the time of the operation the blue book did not stipulate that a doctor should disclose a financial interest in a hospital to which he refers a patient, but the latest edition makes this clear. The case of James McAlpine is a cautionary tale, particularly on the question of informed consent but also on the disclosure of financial interests, the need for certainty about who is to be responsible for the patient's care at every stage, and more specifically the role of radiologists who carry out interventionist procedures.

Mr Webster was consultant plastic surgeon at Canniesburn Hospital in Glasgow and at Seafield Children's Hospital in Ayr when James McAlpine, whose family were members of BUPA, was referred by his general practitioner for an opinion on the haemangioma, which varied in size

\section{London NW1}

CLARE DYER, BA, BLS, solicitor and legal journalist between $1 \mathrm{~cm}$ and $2 \mathrm{~cm}$ in diameter, becoming more prominent in cold weather. He also had admitting rights at two private hospitals, including Ross Hall, in which he was a major shareholder, with shares worth around $£ 27000$.

In evidence to the professional conduct committee $\mathrm{Mr}$ Webster said that he had advised against surgery, which he thought would be disfiguring, and against doing nothing, because he believed the lesion might grow further. He suggested a third possibility: to insert a small catheter into the blood vessels and possibly block them off; this was a technique, he told the parents, which entailed radiography and also a general anaesthetic. The parents were not told that $\mathrm{Mr}$ Webster would not carry out the procedure himself. In evidence to the committee he said he assumed that they would understand that he meant he would arrange for somebody else to do it. There was no mention of any risks attached to the technique. At the time, $\mathrm{Mr}$ Webster told the GMC, "I did not think that the risk was life threatening. I did not think it could be equated to a major operation. Possibly it could be equated to a minor operation such as tonsillectomy."

\section{A tale of two neuroradiologists}

The neuroradiologist Mr Webster first approached, Dr Evelyn Teasdale of the Institute of Neurological Sciences, Southern General Hospital, Glasgow, refused to carry out the operation outside her own hospital, where (she pointed out in a letter to $\mathrm{Mr}$ Webster) private beds were available. The reason she gave was that "the techniques for embolisation are far from standard or simple" and "it is done best when assisted by a team with experience and when using equipment, both instruments and $x$ ray apparatus, with which one is very familiar." $\mathrm{Dr}$ Teasdale told the professional conduct committee that she had performed the procedure on around 105 patients, one of whom had been left with a permanent neurological deficit and three with a transient neurological deficit. It had been her practice for some time to warn patients that the procedure carried a $1 \%$ risk of a stroke and a $3 \%$ risk of temporary weakness.

Dr Vaughan, consultant neuroradiologist at the Western General Hospital in Edinburgh, agreed to carry out the procedure at Ross Hall. Dr Vaughan did not see James or his mother until the morning of the operation. On that morning he and the anaesthetist, Dr Douglas Arthur, a consultant at the Royal Hospital for Sick Children and Glasgow Royal Infirmary who had anaesthetised for this procedure on several previous occasions, separately saw Mrs McAlpine and explained the procedure but said nothing about risk. Dr Vaughan told the GMC that if any risk arose in any radiological procedure it was the practice in Edinburgh to discuss this with the referring clinician, who would put the facts to the patient. All Dr Vaughan had told Mr Webster on this point, however, was that he had had "no trouble" with the procedure. In his evidence he said that he knew that Mr Webster had referred similar cases previously to Dr Teasdale and assumed that he was competent to explain the procedure.

Dr Vaughan, who at the time of the operation had done about 50 external carotid embolisations since he had begun using the procedure in 1978 (though he had no experience of embolisation for haemangiomas of the lip), told the GMC that he had not come across a case of inadvertent embolisation into the internal carotid artery in his unit. At the time he would have thought such an event, given proper care, extremely unlikely, he said. "At the end of the day you have to speak from your own experience, and my experience had been one of a clean sheet. I would have to load things in that fashion and not give undue anxiety to people."

This approach was criticised by Mr Justice Skinner, the trial judge in Sidaway $v$ The Bethlem Royal Hospital, the leading case on informed 
consent, and again by Sir John Donaldson, the Master of the Rolls, when the case went to the Court of Appeal: "In my judgment Skinner J was right to reject the approach of Professor Logue, which was not to refer to small risks if he thought that, in his hands, they were trivial." The House of Lords' decision in Sidaway, handed down the day before James McAlpine's operation, confirmed that a doctor's failure to warn of a risk will not normally be negligent, as long as he is acting in accordance with the practice of a responsible body of medical opinion (though two of the law lords indicated that disclosure of the risk of some serious adverse consequences might be so necessary to enable the patient to make a balanced judgment that no prudent doctor could reasonably omit it; the example given was a $10 \%$ risk of a stroke).

In the Sidaway case a neurosurgeon who had failed to warn of a less than $1 \%$ risk of damage to the spinal cord from an operation to relieve neck and shoulder pain was held not negligent. Counsel for Dr Vaughan submitted that, on the basis of Sidaway, it was strongly arguable that the failure to warn of the risk of death in this case would not have amounted to negligence, let alone serious professional misconduct. But the GMC's expert witness, Professor David Allison, director of diagnostic radiology at the Royal Postgraduate Medical School, Hammersmith Hospital, and a leading authority on embolisation, told the committee: "If you give a patient with a lesion on the face, which is only causing a cosmetic problem, a stroke, that is a risk which is out of all proportion to the apparent numerical magnitude of the risk when one expresses a risk of, say, $1 \%$." Counsel for the GMC submitted that no member of the committee, having heard the evidence of the McAlpines, could believe that there was a chance that, had the risks been pointed out, they would have agreed to allow this procedure to be carried out on a child of 7 whose lesion was giving him hardly any cause for concern.

Professor Allison, who told the committee that he had done several hundred embolisations and was currently performing at least two a week, said the technique of external carotid embolisation was anything but simple. The penalties for failure or incompetence were so great that doctors were always very much more worried when working in this territory than elsewhere in the body. He said it was an absolute and invariable rule for him to leave patients in no doubt that the procedure entailed a small but real risk of their becoming blind in one or both eyes or suffering a stroke or serious brain damage that could possibly even kill them. The procedures were so complicated, he said, and the questions that might be asked so varied that it was essential that the person doing the procedure was the one who spoke to the parents and relatives. Once a radiologist moved into intervention he was taking on himself a mantle of clinical responsibility.

Professor Allison said that he clinically examined every patient to try to determine whether the lesion was suitable for embolisation. It could be treated by embolisation if it was predominantly arterial but not if it was predominantly venous. If he thought it was a venous lesion he would not even proceed to arteriography, which itself carried a small risk. (Dr Vaughan had looked at the lesion on the morning of the operation but did not palpate it.)

\section{Confusion after the operation: whose patient was the child?}

After the operation, which finished at 1130 am, Dr Arthur examined James McAlpine and decided that the neurological signs were satisfactory. Dr Vaughan left the hospital at $115 \mathrm{pm}$ to return to Edinburgh, having left instructions that the nurses should visit James frequently. He told the committee that he saw no indications for specific neurological nursing.

It was only after $1030 \mathrm{pm}$, when James was unable to stand on being taken to the lavatory, that regular neurological observations began to be taken, and it was noticed that James seemed to be developing left hemiplegia. Dr Arthur and $\mathrm{Mr}$ Webster were called in, and Mr Webster telephoned Dr Vaughan after examining James. Dr Vaughan did not return to the hospital. On the basis of Mr Webster's description he told the committee that he thought the cause was probably spasm, because there seemed to be a trace of weakness rather than a fixed deficit. After examining James again $\mathrm{Mr}$ Webster and Dr Arthur decided at 1 am to transfer him to Yorkhill Children's Hospital, where computed tomography was available. Dr Vaughan was telephoned again and advised computed tomography at around 900 am the next morning. James arrived at Yorkhill at $210 \mathrm{am}$. It was suggested to $\mathrm{Mr}$ Webster that he might consult Dr David Mendelow, an authority on cerebral oedema, but he decided against calling him until later in the morning. At 525 am there was a sudden deterioration in James's condition and intermittent positive pressure ventilation was applied, but tests at 630 am showed him to be brain stem dead.

Dr Vaughan, Mr Webster, and Dr Arthur all said in evidence that they had discounted the possibility of embolisation of the internal carotid artery, because in that case they would have expected neurological signs to appear quickly. Professor Allison agreed that this would normally be the case but said that it was conceivable that, particularly in a child, embolic material might be deposited in cerebral vessels without any gross neurological deficit becoming apparent immediately, but over the course of time, as thrombosis occurred, incited by the presence of that material, more peripherally the cerebral cortex would become infarcted and then produce cerebral oedema.

Had the operation been carried out at the Institute of Neurological Sciences, Dr Teasdale told the committee, there would have been a routine follow up, with particular attention being paid to the central nervous system, by nursing staff who were all familiar with the technical aspects of embolisation and its potential complications. Professor Allison said that although there was no record in the $x$ ray film to say that embolisation had occurred, there was plenty of evidence to ring the loudest of alarm bells in the mind of any interventional radiologist: reflux of contrast medium into the internal carotid, and emboli present in all the external carotid branches and within a few millimetres of the bifurcation. Having seen the pictures that raised the alarm that there was the possibility of internal carotid embolisation, he said that it would have been prudent to adopt a regimen under which it would become immediately apparent if this had, in fact, occurred.

The evidence in the case suggests, in the words of the chairman of the professional conduct committee, that "there was a large measure of uncertainty as to where responsibility lay in the care of this child." $\mathrm{Dr}$ Vaughan said that he had assumed that $\mathrm{Mr}$ Webster had the continuing responsibility for the patient, because "I was operating on a patient in his bed." Mr Webster said that he did not consider himself to be primarily responsible.

\section{New guidelines and two final lessons}

As a result of this case the Royal College of Radiologists intends to formulate guidelines for interventionist radiologists on the explanation of risks to patients. But, whatever other lessons may be learnt from the death of James McAlpine, at least two warnings emerge clearly. A doctor should never take it on himself to explain a procedure unless he himself fully understands it, including its attendant risks. And a radiologist who undertakes an invasive procedure should examine and assess the patient beforehand and discuss the procedure with the patient or, in the case of a child, his parents, making sure he gives enough information about the hazards to allow them to form a balanced judgment about going ahead with the procedure.

The British Dental Association has recommended that dental surgery assistants should receive vaccination against hepatitis $B$. What is the incidence of hepatitis $B$ occurring in dental surgery assistants in comparison with other groups potentially "at risk" such as policemen and ambulancemen?

There is good evidence that all dental health care staff working directly with patients, and not just oral surgeons, are at risk of contracting hepatitis B virus (HBV) infection. ${ }^{1.3}$ In a large Veterans Administration Cooperative Study $24 \%$ of oral surgeons, $16 \%$ of general dentists, $17 \%$ of dental hygienists, $14 \%$ of dental technicians, and $13 \%$ of dental surgery assistants were seropositive for anti-HBc or anti-HBs, indicating past exposure to $\mathrm{HBV}$, compared with under $1 \%$ of non-clinical staff, ${ }^{1}$ and the risk was similar for community and hospital based practices.$^{1.3}$ These findings form the basis of the recommendations by the British Dental Association that all clinical dental staff should be offered vaccination against HBV. Furthermore, since the risk (seroconversion rate) increases with age, reflecting the number of years in clinical practice, ${ }^{2}$ the hepatitis $B$ vaccine should be offered as early as possible. Comparable data for policemen or ambulancemen are not available. Certain subgroups within these services-for example, drug squad and prison officers-are likely to be exposed to HBV through contact with the blood or body secretions of high risk individuals such as drug addicts, and should be considered for vaccination. In the United Kingdom, however, emergency service and rescue personnel on general duties are unlikely to have any higher degree of exposure to high risk individuals than nurses and doctors working on general wards who are not at particularly high risk and have therefore not been offered the hepatitis B vaccine. ${ }^{3}$ - ELIZABETH FAGAN, lecturer, liver unit. London.

1 Shiff ER, de Medina M, Woodman S, Katz B, Kline S. VA Cooperative Study on hepatitis and dentistry. Hepatology 1982;2:688.

2 Epstein JB, Buchner BK, Bouchard S. Hepatitis B and Canadian dental professionals. Fournal of Canadian Dental Association 1984;7:555-9.

3 Vandervelde EM, Mortimer PP. New hepatitis B vaccines. Br Med f 1985;290:787. 